\title{
Arquivos e Arquivologia na França e no Brasil: marcos históricos e contextos singulares
}

\author{
Archives and Archival Science in France and in Brazil: \\ Historical Landmarks and Singular Contexts
}

\author{
Angelica Alves da Cunha Marques* \\ Georgete Medleg Rodrigues* \\ Christine Nougaret $^{* * *}$
}

\section{RESUMo}

Este artigo apresenta alguns marcos da institucionalização da Arquivologia na França e no Brasil, em suas singularidades (e não comparativamente), pressupondo duas realidades distintas. Com base em pesquisa documental e bibliográfica em instituições brasileiras e francesas, além de entrevistas com professores, pesquisadores e arquivistas franceses, o artigo busca demonstrar as realidades dos dois países, ainda que, em muitos aspectos, o Brasil seja considerado tributário da experiência institucional francesa. Os resultados apresentam, da parte francesa, mais detalhadamente, marcos da trajetória teórico-epistemológica da Arquivologia e político-institucional dos Archives Nationales, dos cursos de formação de ar-

\section{Abstract}

This paper presents some landmarks of the institutionalization of Archival Science in France and in Brazil, in their singularities (and not comparatively), assuming two different realities. Based on a documental and bibliographical research in Brazilian and French institutions, in addition to interviews with French professors, researchers, and archivists, this paper aims to demonstrate the realities of these two countries, even though that, in many aspects, Brazil is deemed as tributary to the French institutional experience. The results show, on the French side, in more detail, landmarks of the theoretical-epistemological path of Archival Science and the political-institutional path of Archives Nationales, of archivists' formation courses,

\footnotetext{
* Universidade de Brasília (UnB), Faculdade de Ciência da Informação, Curso de Arquivologia. Brasília, DF, Brasil. angelicacunha@unb.br <https://orcid.org/0000-0003-4642-5912>

** Universidade de Brasília (UnB), Faculdade de Ciência da Informação, Curso de Arquivologia. Brasília, DF, Brasil. georgete@unb.br <https://orcid.org/0000-0002-6446-6171>

*** Université PSL (Paris Sciences \& Lettres), École Nationale des Chartes. Paris, France. christine. nougaret@enc-sorbonne.fr <https://orcid.org/0000-0003-4803-2901>
} 
quivistas - especialmente da École Nationale des Chartes e da Association des Archivistes Français -, da revista Gazette des Archives e das classificações dos arquivos e da disciplina pelas instituições da França. Da parte brasileira, apresentam, mais sinteticamente, as instituições e suas iniciativas para a criação de cursos voltados à formação de arquivistas no Brasil.

Palavras-chave: Arquivologia; Brasil; França; instituições de arquivo; interlocuções internacionais. especially of the École Nationale des Chartes, of the Association des Archivistes Français, of the magazine Gazette des Archives, and of the classifications of archives and of the discipline by French institutions. On the Brazilian side, results show, more synthetically, the institutions and their main initiatives for the creation of courses for the formation of archivists in Brazil.

Keywords: Archival science; Brazil; France; archive institutions; international interlocutions.

No decorrer de alguns anos de estudo, participamos de um amplo projeto de pesquisa, desdobrado em quatro fases, de 2002 a 2015. ${ }^{1}$ Nas primeiras fases, a análise da trajetória da Arquivologia no Brasil demonstrou que a sua formação, como disciplina, foi consequência direta e imediata da necessidade prática de habilitação de profissionais especializados para a organização dos arquivos públicos brasileiros, com liderança do Arquivo Nacional (AN) e da Associação dos Arquivistas Brasileiros (AAB). A realização de diversos cursos pelo AN foi essencial para a implementação do primeiro curso regular de formação de arquivistas, o Curso Permanente de Arquivos (CPA), em 1960, que, por sua vez, subsidiou a conquista de espaços universitários pela Arquivologia. Essa conquista definiria os rumos e a configuração da disciplina no cenário brasileiro, a partir das recomendações do arquivista francês Boullier de Branche (Marques, 2007) que mesmo em um contexto de avanço do pensamento norte-americano, vem ao Brasil, faz um diagnóstico dos arquivos brasileiros e ministra aulas em cursos que, saberíamos mais tarde, seriam o embrião do CPA.

Acerca da configuração atual da Arquivologia no Brasil, observamos diversos diálogos estabelecidos entre esta e outras disciplinas, quanto aos vínculos institucionais dos seus cursos de graduação, à formação/titulação dos docentes desses cursos e à produção científica da área ou a ela afim. Esses três aspectos apontam para uma intensa proximidade entre a Arquivologia e a Ciência da Informação (CI) - sobretudo político-institucional, inclusive na perspectiva acadêmica -, embora a sua trajetória tenha sido marcada pela tradição histórica, decorrente da atuação do AN. Desse modo, constatamos 
na configuração da Arquivologia, conforme as particularidades brasileiras, a predominância da vertente histórica, em um primeiro momento, e, posteriormente, da vertente informacional, que procura se integrar aos vários contextos de produção e usos da informação. Contudo, essas perspectivas não são consensuais entre os autores da área e, por vezes, geram polêmicas, nem sempre correspondem ao debate internacional a respeito da gestão documental, conforme veremos mais adiante, na seção que apresentará os arquivos e a Arquivologia franceses muito próximos da História ao longo do tempo e na contemporaneidade.

Em síntese, essas particularidades relacionam-se: à predominância da formação/titulação dos docentes dos cursos de Arquivologia do Brasil em CI; à vinculação acadêmico-administrativa dos cursos de graduação em Arquivologia a departamentos, faculdades e institutos de CI/Documentação, ainda que nem todos os cursos estejam assim vinculados administrativamente; ao compartilhamento do mesmo espaço acadêmico-institucional entre cursos de Arquivologia e programas de pós-graduação em CI; à presença simultânea de professores nos cursos de graduação em Arquivologia e nesses programas; à produção científica relacionada aos arquivos e à Arquivologia nos mesmos programas; à vinculação político-institucional da Arquivologia à CI, de acordo com a Tabela de Áreas do Conhecimento (TAC) do CNPq (Conselho Nacional de Desenvolvimento Científico e Tecnológico, 1984).

Assim, apesar da tradição histórica da Arquivologia, marcada pela atuação do AN, sua atual proximidade com a CI, perpassada pelo seu processo de autoafirmação como disciplina científica, nos apontou que, em algum momento da sua trajetória, a Arquivologia aproximou-se da CI (ou, pelo menos, de seus discursos) para se acomodar no campo da informação e nele encontrar abrigo acadêmico-institucional. Essa nova configuração da Arquivologia nos últimos anos parece decorrer, portanto, das suas necessidades de se acomodar a uma área acadêmico-institucional, mais do que de interlocuções teórico-epistemológicas entre as duas disciplinas (Marques, 2017).

Diante dessas constatações, questionamos o que teria subsidiado os diálogos entre a Arquivologia e a CI no Brasil, de uma parte; de outra, qual seria a herança arquivística francesa para a Arquivologia brasileira, em decorrência das diversas contribuições de arquivistas, professores e pesquisadores franceses que vieram ao Brasil no âmbito de várias iniciativas, inclusive do próprio AN.

Este artigo é, assim, um recorte dos resultados da pesquisa realizada desde 2014 e apresenta alguns marcos da institucionalização da Arquivologia na 
França e no Brasil, em suas peculiaridades (e não comparativamente), uma vez que se referem a duas realidades distintas. $\mathrm{O}$ estudo nutriu-se de uma extensa pesquisa documental e bibliográfica em instituições brasileiras ( $\mathrm{AN}$ e $\mathrm{CNPq}$ ) e francesas (Archives Nationales, Archives Diplomatiques e École des Hautes Études en Sciences Sociales - EHESS), além de entrevistas com professores, pesquisadores e arquivistas franceses que colaboraram para a institucionalização da Arquivologia no Brasil. ${ }^{2}$

A opção pelo estudo das interlocuções arquivísticas entre Brasil e França resultou das suas relações seculares, especialmente aquelas empreendidas a partir da cooperação cultural entre os dois países, oficializada pelo acordo de 6 de dezembro de 1948 (Accord Culturel entre le Gouvernement de la République Française et le Gouvernement de la République des États-Unis du Brésil, 1948) e, mais particularmente, da herança institucional do AN do Brasil em relação à França (Estevão; Fonseca, 2010).

Nas seções seguintes apresenta-se uma síntese da trajetória teórico-epistemológica da Arquivologia na França e político-institucional dos Archives Nationales, dos cursos de formação de arquivistas - em especial da École Nationale des Chartes (ENC), da Association des Archivistes Français (AAF) -, da Gazette des Archives e das classificações dos arquivos e da disciplina pelas instituições francesas. Da parte brasileira, são apresentadas as instituições e as suas iniciativas para a criação de cursos voltados à formação de arquivistas no Brasil.

\section{Os arquivos e a Arquivologia na França}

Robert-Henri Bautier (1968) esquematiza a história dos arquivos em quatro períodos: 1) archives des palais (Antiguidade); 2) trésors des chartes, títulos comprobatórios de direitos (do século XII ao XVI); 3) archives arsenal de l'autorité (século XVI ao início do século XIX); 4) archives laboratoires de l'histoire (início do século XIX até meados do século XX). Os depósitos de arquivo são constituídos e a Arquivologia nasce, de acordo com Bautier, no terceiro período.

O prenúncio do que viria a ser a Arquivologia francesa remonta ao século XVII, com uma obra que consagraria a Diplomática, em 1681: De Re Diplomatica, do monge beneditino Jean Mabillon, cujos estudos são seguidos por outros beneditinos franceses (Bautier, 1968). A partir dessa publicação, 
diversas universidades criam cadeiras de Diplomática e Paleografia: Bolonha (1765), Milão (1770), Nápoles (1777), Coimbra (1796), Turim (1820) e Madri (1839) (Delmas, 2006).

A ENC é criada em 1821, em Paris, no contexto que precede o Romantismo literário e político - no qual o trabalho histórico se apoia nos documentos de arquivo (Bautier, 1968) - para formar arquivistas-paleógrafos, ligada ao Cabinet des Chartes, que buscava centralizar os documentos dispersos nos diversos arquivos do reino e copiar todos os documentos de interesse à história da França, para formar uma coleção na Bibliothèque Royale (Langlois; Stein, 1891; Langlois, 1895; Delmas, 2006). Vinculada, portanto, à biblioteca, a ENC abriga duas tradições: a conservação empírica de documentos e a política documental de seleção, concentração e comunicação de documentos históricos, contemplados como monumentos. Em 1847, a escola se desvincula da Bibliothèque Royale e se instala nos Archives Royales, rompendo a política com o Cabinet des Chartes (Delmas, 2006).

A Diplomática, por sua vez, que estivera recôndita, reaparece ao lado da Paleografia, e a obra de Natalis Wailly (1838), Éléments de Paléographie, simboliza esse movimento. Designado por Guizot ${ }^{3}$ para realizar essa empreitada, Wailly a denomina como "um novo tratado de Diplomática", com mais de mil páginas.

Nesse contexto, o documento é relacionado ao arquivo, na sua erudição histórica, e o interesse pelo documento individual ou pelo conjunto documental define o novo objeto de estudo, o fonds: "conjunto de elementos tangíveis e intangíveis que permite a uma pessoa exercer as suas atividades" (Delmas, 2006, p.8). ${ }^{4}$ Segundo o autor, a ruptura intelectual da Arquivologia com a Diplomática dá-se com a passagem do documento isolado ao fundo. A distinção entre o fundo de arquivo e a coleção de biblioteca vai ao encontro do princípio geral de arranjo dos documentos arquivísticos, por meio do princípio de Respeito aos Fundos, "isto é, o respeito pela natureza orgânica desse conjunto tal como ele foi constituído" (Delmas, 2006, p.9).

Na segunda metade do século XIX a orientação em favor da história nacional se acentua, culminando no interesse pelos arquivos da Idade Média e, consequentemente, no desenvolvimento de inventários. A Arquivologia se apoia, então, em dois eixos: 1) descritivo, como "ciência auxiliar da História", voltada para identificação, classificação e inventário de fontes; e 2) de gestão, dedicada à administração dos serviços de arquivo (especialmente os arquivos 
departamentais), tidos como "laboratórios da história", a serviço da História Positivista (Delmas, 2006).

Ainda segundo Delmas, o primeiro estudioso que teoriza e define a Arquivologia é Charles-Victor Langlois, ${ }^{5}$ em artigo publicado no primeiro número da Revue Internationale des Archives, des Bibliothèques et des Musées, revista que reconhece a existência de uma ciência de arquivos, de uma ciência de bibliotecas e de uma ciência de museus, especificamente auxiliares de outras ciências. Inicialmente, Langlois apresenta uma definição de "arquivo": "o depósito de títulos e documentos autênticos de toda espécie que interessem a um Estado, uma província, uma cidade, uma instituição pública ou privada, uma empresa, um indivíduo" (Langlois, 1895, p.7). A "Science des Archives" (Ciência dos Arquivos), título de seu artigo, por sua vez, "trata da economia, da organização teórica, descritiva e comparativa e da história dos depósitos de arquivos, que lista esses depósitos e que divulga os repertórios" (Langlois, 1895, p.7-8). Contudo, depois de mencionar manuais, repertórios de arquivos e revistas de diversos países, Langlois reconhece a imaturidade da ciência e de suas práticas.

Esse trabalho retoma, portanto, o inventário dos estabelecimentos onde os arquivos da França eram conservados, em território nacional ou estrangeiro, feito alguns anos antes por Langlois e Henri Stein (Langlois; Stein, 1891), por sua vez, inspirados nas ideias de Moreau, ${ }^{6}$ consubstanciadas no Cabinet des Chartes. Esses arquivos compreendiam "a coleção de todos os documentos dos arquivos relativos à história da França” (Langlois; Stein, 1891, p.10). Para Delmas (2006, p.11), embora o Respeito aos Fundos tenha perpassado a descrição empreendida por esses estudiosos, não se tinha uma "teoria de fundos". Havia, portanto, diversidade e confusão metodológica. Ainda de acordo com esse autor, no final do século XIX a Arquivologia desdobra-se em três eixos: história dos depósitos dos arquivos, arquivoeconomia (serviço de arquivos) e descrição, caracterizando-se como uma ciência descritiva dos arquivos. Nesse sentido, a obra de Langlois e Stein (1891) teria delineado a "arquivoeconomia francesa” nas perspectivas descritiva e documentária (Delmas, 2006).

A primeira metade do século XX é perpassada por alguns fatos que marcariam a história da Arquivologia na França. Em 1904 é criada a Association Amicale Professionnelle des Archivistes Français (AAPAF), atual Association des Archivistes Français (AAF), cujas contribuições para a disciplina apresentaremos adiante. Em 1910, o $1^{\text {er }}$ Congrès International des Archivistes et des Bibliothécaires, em Bruxelas, ${ }^{7}$ adota e difunde as noções de "Fundo" e de 
"Respeito aos Fundos" (Delmas, 2006). No contexto da Primeira Guerra Mundial, os esforços empreendidos para a constituição da história positivista teriam diminuído e, com o aumento da massa de documentos, os interesses quanto à sua organização se afastaram da História. Em 1921, arquivistas departamentais são reunidos numa única carreira de Estado, institucionalizando a profissão. Em 1933 é criada a revista Gazette des Archives, pela AAF. Para Delmas (2006, p.13), tais fatores são constituintes da formação da identidade da nova geração de arquivistas, permitindo-lhes "pensar sua profissão e sua disciplina como realidades novas e autônomas”.

É nesse contexto que a Arquivologia, descritiva e diante do já delineado conceito de "fundo", busca consubstanciar questões teóricas e práticas aplicadas às atividades dos serviços de arquivos, ou seja, questões técnicas e de gestão, reunidas no âmbito da "arquivoeconomia". No pós-guerra esse ramo desenvolve-se, assim como se acentua o papel da AAF na teoria e nas práticas arquivísticas por parte do Estado francês. Perpassados por reflexões e pela busca de uma terminologia, os termos Archivologie e Archivoéconomie (a partir do século XX) consolidam-se como Archivistique, enquanto a archivation evolui para archivage e abrange questões mais práticas (Delmas, 2006).

Avanços teóricos marcam esse contexto, dos quais Delmas (2006) destaca a "Théorie des trois âges" (Teoria das três idades), inaugurada pelo arquivista Yves Pérotin. De fato, ao considerar a passagem dos documentos administrativos, de primeira idade, aos documentos históricos, de terceira idade, Pérotin acrescenta uma segunda idade, a intermediária, a qual contempla a transição entre a Administração e a História (Pérotin, 1962).

A história dos Archives Nationales e sua influência internacional, por sua vez, estão relacionadas, respectivamente, ao objetivo de sua criação e ao modelo institucional estabelecido num decreto da Assembleia Constituinte de setembro de 1790. Os Archives Nationales foram definidos, em linhas gerais, pela Lei 7 messidor, ano II (25 de junho de 1794) da Convenção Nacional, como o "depósito central para toda a República, de todos os documentos enumerados” na referida lei (Langlois, 1895; Bautier, 1968; Babelon, 2008). ${ }^{8}$ Não somente os documentos do governo francês como, também, os do "grande império" são afetados pela mudança e, desse modo, seria possível gerir de Paris todos os territórios submetidos à sua autoridade (Babelon, 2008).

Sobre a repercussão do modelo institucional então criado, podemos citar a constituição da primeira rede de arquivos regionais na Europa, a qual decorre de uma lei de 1796, que prevê a concentração do conjunto dos documentos de 
arquivo do Antigo Regime nos arquivos departamentais. Do ponto de vista internacional, esse modelo centralizador dos arquivos do Estado teria sido o terceiro, precedido pelos da Espanha (Simancas, século XVI) e pela Áustria, no século XVIII. Sua influência aparece rapidamente na Itália, nos Países Baixos e na Bélgica, levando à organização dos arquivos administrativos desses países (Bautier, 1968).

Em 1791 é criada a Agence temporaire des titres, com o fim de gerir, selecionar e eliminar parte dos documentos reunidos. Entre 1794 e 1801, o Bureau de triage serve às necessidades administrativas e históricas, classificando os documentos segundo os interesses e não conforme as suas origens. Camus $^{9}$ impede que a medida prevista pela Lei do 7 messidor ( 25 de junho de 1794) se cumpra, quanto à transferência de documentos para a Bibliothèque Nationale, segundo seus interesses para a História, as Artes, Letras e Ciências.

Anos mais tarde, em razão das dificuldades decorrentes da dispersão dos lugares de depósito dos arquivos para a sua conservação e consulta, Napoleão Bonaparte os reúne em um único lugar, em 1808: o Palais de Soubise, destinado a acolher "todos os arquivos existentes em Paris, sob qualquer denominação que pudessem ter” (Babelon, 2008, p.17). Depois da centralização dos arquivos nesse palácio (Decreto imperial de 6 de março de 1808), os Archives Nationales são divididos em três seções (histórica, administrativa e judiciária), em 1846. Em 1897 são criadas diferentes seções cronológicas para o arranjo de documentos. Decreto de 21 de julho de 1936 torna obrigatório o recolhimento dos documentos dos ministérios e das administrações que deles dependem aos depósitos de arquivos do Estado.

O processo de modernização da organização administrativa é acelerado pela Direction des Archives de France (DAF), em 1945. Em 1952, as missions d'archives são criadas nos ministérios, com o objetivo de coletar os arquivos para preservação permanente nos Archives Nationales. A partir de 1959, os Archives Nationales passam a ser o órgão central da DAF. ${ }^{10} \mathrm{~A}$ direção, como coração de uma rede, elabora orientações para o tratamento dos arquivos e dá o apoio técnico por meio dos inspetores gerais (Babelon, 2008).

Os anos 1970 assistem à criação de mais um prédio dos Archives Nationales em Fontainebleau, assim como à criação de seções de arquivos privados, econômicos e associativos em Paris (Babelon, 2008). Em 2013 inaugura-se o prédio de Pierrefitte-sur-Seine, ${ }^{11}$ compondo, com os estabelecimentos do centro de Paris, de Fontainebleau, dos Archives nationales d'outre-mer 
(Aix-en-Provence) e dos Archives nationales du monde du travail (Roubaix), os serviços arquivísticos de competência nacional.

Segundo Delmas (2006), a contribuição dos Archives Nationales quanto à formação profissional está relacionada à Arquivoeconomia, com a oferta do Stage Technique International des Archives (STIA), desde 1951. Esse estágio é desde então oferecido na sede daquela instituição em Paris, incluindo visitas técnicas a arquivos de outras regiões francesas. ${ }^{12}$

A ENC, por sua vez, é fundada por Joseph Marie de Gérando ${ }^{13}$ em fevereiro de $1821,{ }^{14}$ inspirada na vontade de formar especialistas na leitura de escrituras antigas (Babelon, 2008, p.65). A ENC oferece formação de erudição pura ou quase pura (Braibant, 1949), embora a instituição busque uma renovação regular na formação de arquivistas-paleógrafos (Nougaret, 2007). A missão primordial da ENC é a formação no âmbito da conservação, ao contemplar a atuação dos profissionais em bibliotecas, museus, monumentos históricos e arquivos, tanto do setor público quanto do privado. Ainda há, de acordo com Nougaret (2007), possibilidades de carreira no ensino superior e na pesquisa, além de empregos na alta administração. A ENC forma arquivistas, mas não somente. De acordo com Nougaret (2007) a instituição oferece o curso para a formação de arquivistas paleógrafos ( 3 anos) e o mestrado de 2 anos, que combina erudição e Ciências da Informação sob a denominação "Nouvelles technologies appliquées à l'Histoire". Ainda que não forme somente arquivistas e pontualmente tenha oferecido disciplinas dedicadas ao estudo da CI na década de 1980 (Delmas, 1988), sua abordagem está ancorada no domínio arquivístico, especialmente quanto aos arquivos modernos e contemporâneos.

Os conservadores formados pela ENC são recrutados pelos arquivos públicos. A partir de um decreto de 1850, passam a ter postos reservados como arquivistas dos départements e, depois, com um decreto de 1887, como conservateurs d'archives aux Archives Nationales. Desde 1991, o diploma de archiviste-paléographe já não é suficiente para ser um arquivista: a passagem por uma nova instituição, a École Nationale de Patrimoine, agora Institute National du Patrimoine (INP), é obrigatória: os aprovados no exame de admissão no INP devem passar 18 meses no Instituto para obter o título de conservateurs $d u$ patrimoine e serão designados a um serviço de arquivo (Archives Nationales, Départamentales, Affaires Étrangères, Défense, Finances) (Babelon, 2008).

Além desses cursos oferecidos pela ENC, existem cursos de formação para arquivistas na França, nas modalidades "profissional”, especialização e 
mestrado, em geral como habilitação dentro de outros cursos (Archives de France, 2018b).

A AAF é outra instituição com papel relevante para a institucionalização da Arquivologia na França. Criada como Association Amicale Professionnelle des Archivistes Français (AAPAF), em 1904, a AAF ocupar-se-ia de todas as questões técnicas e científicas concernentes à profissão do arquivista (Nougaret, 2006). Para Christine Nougaret, a realização mais emblemática da AAF é a Gazette des Archives, criada em 1933. A publicação é interrompida em 1939, em razão da Segunda Guerra Mundial, e a AAF desaparece no ano seguinte. Seis anos depois, a associação retoma suas atividades, com a publicação da revista em 1947, em cooperação com os Archives Nationales.

A publicação do Manuel d'Archivistique, pela AAF, em 1970, colabora com o clima de efervescência teórica alimentado pela Gazette des Archives ao longo das suas edições (Nougaret, 2006). Trata-se de obra coletiva que inclui dois textos introdutórios: o primeiro com definições gerais e problemas jurídicos dos arquivos, de Robert-Henri Bautier; o segundo, sobre a organização e a legislação dos Archives de France desde o século XIX, de Guy Duboscq. A obra divide-se em quatro partes: 1) Arquivologia geral; 2) Arquivologia especial; 3) Conservação material dos documentos; 4) Papel científico, cultural e administrativo dos arquivos (Direction des Archives de France, 1991). Como o próprio título indica, a obra se propõe a apresentar a teoria e a prática dos arquivos públicos franceses. É interessante observar no livro a perspectiva ampliada de "arquivos", pautada na origem da Arquivologia francesa (que contemplaria o duplo papel dos arquivos, sob o olhar das administrações e sob o olhar da pesquisa científica), considerando a "continuidade orgânica" dos documentos. Esse manual teria sido concebido para cobrir uma lacuna na literatura da área à época, de forma a descrever as práticas arquivísticas regulamentadas e, em certa medida, perpassadas por "uma doutrina de conjunto" (Dousset, 1991): práticas e doutrina por sua vez perpassadas por uma vasta rede de trocas diante da internacionalização da área.

Vinte e três anos depois do Manuel d'Archivistique, a DAF publica $L a$ pratique archivistique française (DAF, 1991a), organizada por Jean Favier, então membro da DAF, com o auxílio de Danièle Neirinck, conservateur général encarregada do serviço técnico. A exemplo da primeira obra, esta se propõe a ser um manual de uso prático e não um tratado. A introdução apresenta e discute as definições de arquivo, arquivistas e Arquivologia. O livro é também dividido em quatro partes: 1) Produtores e serviços jurídicos de arquivos; a 
evolução da produção administrativa e da sua utilização; 2) O tratamento de arquivos; 3) Os arquivos e seus públicos; 4) A conservação. Como no primeiro manual, nesta obra é interessante observar que na segunda parte, mais especificamente no segundo capítulo, intitulado "Os arquivos contemporâneos ou a chegada do fluxo ao cotidiano", as autoras apresentam a teoria e a prática do pré-arquivamento, considerando as três idades dos arquivos; a gestão dos arquivos correntes; os arquivos intermediários e o pré-arquivamento (Pétillat; Prax, 1993).

O terceiro grande manual francês no âmbito dos arquivos e da Arquivologia é publicado pela AAF: Abrégé d'Archivistique: principes et pratiques du métier d'archiviste, cuja primeira edição é de 2004 (as seguintes viriam em 2007 e 2012). Com um comitê de redação composto por diversos especialistas, a obra compõe-se de nove capítulos: 1) Arquivos e arquivistas no seu ambiente; 2) Os documentos de atividade na idade corrente e intermediária; 3) Constituição dos arquivos definitivos; 4) Classificação e codificação; 5) Análise e indexação; 6) Instrumentos de pesquisa: princípios e atualização de novas tecnologias; 7) Do pergaminho ao arquivo eletrônico: conservação e perenidade; 8) Comunicação de documentos de arquivo; 9) Valorização dos arquivos (Association des Archivistes Français, 2012). Novamente, observamos um manual francês contemplar questões relacionadas aos arquivos correntes e intermediários, como ocorre no segundo capítulo desse livro, que abrange os documentos no seu contexto de produção; a gestão de documentos no âmbito das organizações; a expertise do arquivista; os instrumentos de gestão (plano de classificação, plano de conservação, diagnóstico).

Para Marcilloux (2012), a institucionalização da Arquivologia na França dá-se de forma plural, ainda que instituições francesas não reconheçam os arquivos e a Arquivologia, na maioria dos casos. A falta de reconhecimento ou o reconhecimento implícito da Arquivologia são entendidos por Marcilloux (2012, p.303) num quadro de "silêncios oficiais", marcado por incertezas existenciais, taxonômicas e de definições.

Em relação à formação profissional, é o INP que forma o conservateur d'archives, enquanto a École Nationale Supérieure des Sciences de l'Information et des Bibliothèques (ENSSIB) forma o conservateur des bibliothèques e a École du Louvre forma o conservateur de musée ou des monuments historiques et de l'inventaire.

O Dictionnaire des compétences do Ministère de l'Enseignement Supérieur et de la Recherche contempla o métier em emplois-types, ordenado por ramos 
profissionais. São elencadas 18 áreas, dentre as quais a de Documentation-Archives-Bibliothèque. Nela, a Arquivologia é descrita como "Conhecimento dos princípios e técnicas que regem a criação, avaliação, acumulação, classificação, descrição, indexação, divulgação e preservação de arquivos" (Ministère de l'Éducation Nationale; Ministère de l'Enseignement Supérieur et de la Recherche, 2011, p.16).

\section{Os ARquivos E A Arquivologia NO Brasil ${ }^{15}$}

No caso do Brasil, observamos, com base nos documentos pesquisados, uma convergência de esforços (do Estado, das associações e das instituições de arquivo) para institucionalizar academicamente a Arquivologia. O Arquivo Nacional (AN), instituição criada como Arquivo Público do Império (1838), já no século XIX demonstrava preocupações quanto à criação de cursos para a formação de pessoal habilitado para organizar os seus arquivos, chegando a reconhecer a necessidade de formação em cursos específicos como condição para ocupação dos seus cargos técnicos (Marques, 2007; 2011).

No século XX observamos inquietações mais consistentes quanto ao desenvolvimento da Arquivologia no Brasil, por meio de documentos do AN que insistem na formação especializada dos seus funcionários e pela concepção de cursos (Curso de Diplomática, 1911; Curso Técnico, 1916; Curso Técnico de Arquivos, 1923; Curso Técnico, 1931; solicitação de inclusão do curso de Arquivologia na Universidade do Rio de Janeiro, em 1930). Alguns diretores dessa instituição esforçam-se por suprir o aperfeiçoamento do pessoal técnico da instituição com o compartilhamento de experiências por profissionais que tivessem viajado para o exterior.

Avanços significativos podem ser verificados a partir da concepção do cargo de arquivista em alguns quadros da Administração Pública, ainda que de forma escalonada (1936) e com desdobramentos da carreira de arquivista com a reforma dos quadros ministeriais (1941); da atuação do Departamento Administrativo do Serviço Público (Dasp) na gênese da Documentação no Brasil; do início da cooperação arquivística internacional, com a vinda de um historiador norte-americano ao AN (1944); das primeiras participações de brasileiros em cargos e comitês de instituições internacionais, com destaque para o Conseil International des Archives (ICA). 
Na década de 1950 a cooperação arquivística internacional se intensifica, com a vinda de professores e pesquisadores estrangeiros (norte-americanos e franceses), o início da participação de brasileiros no STIA, a continuidade da participação de brasileiros em cargos e comitês de instituições internacionais e a tradução de obras estrangeiras para o português. O AN passa por mudanças em sua infraestrutura, nos moldes norte-americano e inglês, e insiste na necessidade de oferta de cursos de formação de pessoal especializado em Arquivologia, considerando que ainda não contava com nenhum servidor com essa especialização. A instituição começa a ofertar cursos avulsos, de técnicas de arquivo, com a colaboração de um professor francês (1959). No mesmo ano, José Honório Rodrigues realiza um diagnóstico do AN, dos arquivos e da Arquivologia. A Fundação Getúlio Vargas (FGV), por sua vez, destaca-se como instituição pioneira na gestão de documentos.

O AN continua a oferta de cursos avulsos e do primeiro curso regular para a formação do pessoal de arquivo, o CPA, iniciado em 1960, com base nas recomendações do professor francês. O Ministério da Justiça e Negócios Interiores cria a Comissão Nacional de Arquivos (Conar), para estudar a situação dos arquivos brasileiros e as diretrizes adotadas em países estrangeiros (1961) e para efetivar o Sistema Nacional de Arquivos (SNA), depois desdobrado no Sinar. No ano seguinte, o SNA é concebido com base nos trabalhos dessa comissão, por meio de anteprojeto de lei. Em 1962 é também concebida a Escola Nacional de Arquivística (ENA). O AN encaminha ao ministro da Justiça um anteprojeto de decreto sobre o estabelecimento de uma política de recolhimento de documentos oriundos dos órgãos da Administração Direta e Autárquica, por aquela instituição (1967). Em 1968 o SNA é instituído.

A década de 1970 seria o divisor de águas na trajetória da Arquivologia brasileira. A atuação de professores franceses e norte-americanos nas décadas anteriores tem repercussões, e a cooperação arquivística internacional se intensifica com a vinda de professores e pesquisadores estrangeiros (franceses, italianos, espanhóis, norte-americanos, mexicanos, argentinos, colombianos e alemães); a contínua participação de brasileiros no STIA e em cargos/comitês de instituições internacionais, especialmente na Organização das Nações Unidas para a Educação, a Ciência e a Cultura (Unesco), no ICA e na Asociación Latinoamericana de Archivos (ALA); a filiação do AN ao ICA; o início da participação de brasileiros em cursos da Organização dos Estados Americanos (OEA), oferecidos em Madri e Córdoba; o reconhecimento, pelo $\mathrm{AN}$, da necessidade de intercâmbio entre especialistas nacionais e estrangeiros, 
inclusive com o estudo das normas internacionais, para a melhoria da situação arquivística brasileira. Concomitantemente, o CPA também tem repercussões positivas, com o aumento significativo dos inscritos e a reforma do seu currículo. Nesse sentido, observamos preocupações quanto à transferência desse curso para a universidade, por meio de negociações e acordos entre várias instituições públicas. O curso tem seu currículo mínimo e sua duração aprovados em 1975. Um ano depois, seu quadro docente é aprovado, assim como o dos cursos avulsos do AN.

Vários acontecimentos também marcam a história da Arquivologia brasileira nos anos 1970: a criação da Associação de Pesquisa Histórica e Arquivística (APHA) e da AAB (1971); a realização do I Congresso Brasileiro de Arquivologia (CBA), com a recomendação de um currículo mínimo para os cursos de Arquivologia (1972) e participação de estrangeiros no evento; a autorização da criação de cursos de Arquivologia em nível superior, pelo Conselho Federal de Educação (CFE), também em 1972; o reconhecimento da Arquivologia como habilitação profissional no Ensino Médio (1972); o acordo entre a Universidade Federal do Rio de Janeiro (UFRJ) e o AN, regulando o mandato universitário do CPA (1973); o convênio entre a Universidade Federal Fluminense (UFF) e o AN quanto à cooperação em Arquivologia e pesquisa histórica (1974); o estabelecimento da duração do Curso Superior de Arquivologia e do seu currículo mínimo (1974); as tentativas de implantação de cursos de Arquivologia em Brasília e Belo Horizonte; o encaminhamento presidencial, ao Congresso Nacional, da proposta do Sinar; estudos da legislação internacional para o embasamento da Lei de Arquivos; a intensificação das preocupações quanto à oferta de curso regular no âmbito universitário para a formação de arquivistas, com a criação de mais dois cursos em universidades federais, na Universidade Federal de Santa Maria (UFSM) e na Universidade Federal Fluminense (UFF). Surge a primeira dissertação sobre arquivos em um programa de pós-graduação stricto sensu brasileiro (Freitas, 1972).

Nos anos 1980 os movimentos parecem mais silenciosos, mas são condição para os avanços ocorridos na década seguinte. A cooperação internacional continua, a exemplo dos anos anteriores. O AN implementa seu Projeto de Modernização Institucional Administrativa (1981). No contexto mais amplo, publica-se o anteprojeto de lei sobre arquivos públicos e privados; verificamos repercussões internacionais dos avanços arquivísticos brasileiros (Sinar, cursos e infraestrutura do $\mathrm{AN}$ ); a $\mathrm{AAB}$ tem atuação mais tímida como agregadora dos profissionais da área e suspende a publicação da Revista Arquivo \& 
Administração; os arquivos públicos institucionalizam-se progressivamente, $\mathrm{e}$ continua a produção de pesquisas sobre arquivos e Arquivologia nos programas de pós-graduação. Em 1986 é criado o Curso de Organização de Arquivos do Instituto de Estudos Brasileiros (IEB), na Universidade de São Paulo (USP), congregando profissionais com diversas formações em torno da especialização em Arquivologia.

Nos anos 1990 assistimos à continuidade da cooperação internacional entre profissionais de arquivo brasileiros e estrangeiros. $\mathrm{O}$ fato que parece merecer maior destaque nesse contexto é a promulgação da Lei 8.159/1991, a "Lei de Arquivos", que reconhece o dever do Estado de organização e preservação dos documentos públicos e o direito de acesso à informação, pelo cidadão. O Conselho Nacional de Arquivos (Conarq), instituído com base na referida lei, acomoda as antigas preocupações do SNA no Sinar e se responsabiliza pela legislação e normalização arquivísticas. Mais cinco cursos de graduação em Arquivologia são criados - Universidade de Brasília (UnB), em 1990; Universidade Estadual de Londrina (UEL), em 1997; Universidade Federal da Bahia (UFBA), em 1997; Universidade Federal do Rio Grande do Sul (UFRGS), em 1999; e Universidade Federal do Espírito Santo (Ufes), em 1999. Também são criadas a Associação Brasiliense de Arquivologia (Abarq) e a Associação de Arquivistas de São Paulo (ARQ-SP), ambas em 1998. Progressivamente, pesquisas com temáticas relacionadas aos arquivos e à Arquivologia são desenvolvidas nos diversos programas de pós-graduação stricto sensu brasileiros.

No século XXI, os avanços mencionados quanto à cooperação internacional, à institucionalização dos cursos de graduação e à produção científica são intensificados e ampliados. São criados mais nove cursos de Arquivologia - Universidade Estadual Paulista “Júlio de Mesquita Filho" (Unesp), em 2002; Universidade Estadual da Paraíba (UEPB), em 2006; Universidade Federal da Paraíba (UFPB), em 2007; Universidade Federal do Rio Grande (Furg), em 2008; Universidade Federal de Minas Gerais (UFMG), em 2008; Universidade Federal do Amazonas (Ufam), em 2008; Universidade Federal de Santa Catarina (UFSC), em 2009; Universidade Federal do Pará (UFPA), em 2011; e no Centro Universitário Assunção (Unifai), em 2015. Quanto às associações, são criadas mais sete: Associação dos Arquivistas da Bahia (AABA), em 2002; Associação dos Arquivistas do Estado do Rio de Janeiro (AAERJ), em 2004; Associação dos Arquivistas do Estado do Espírito Santo (AARQES), em 2005; Associação dos Arquivistas do Estado do Paraná 
(AAPR), em 2005; Associação de Arquivologia do Estado de Goiás (AAG), em 2006; Associação dos Arquivistas do Estado do Ceará (Arquive-CE), em 2015; Associação dos Arquivistas do Estado de Santa Catarina (AAESC), em 2015 e Associação dos Arquivistas da Paraíba (AAPB), em 2015.

De modo geral, ao analisar todos esses fatos que marcaram a trajetória dos arquivos e da Arquivologia brasileira, observa-se como demandas do mundo do trabalho podem justificar a institucionalização de uma disciplina, especialmente a sua conquista de espaço na universidade. A partir das sucessivas iniciativas do AN, desde o final do século XIX e intensificadas ao longo das décadas seguintes, as necessidades de formação técnica do arquivista diante das demandas de organização e preservação dos documentos acumulados, sobretudo pelas instituições públicas brasileiras, foram explicitadas em vários documentos, inclusive em regulamentos e decretos. Nessa perspectiva, os discursos de diretores e funcionários do $\mathrm{AN}$, bem como de arquivistas, professores e pesquisadores estrangeiros (aqui destacamos os autores franceses, especialmente Boullier de Branche), convergiram para recomendações de implementação de cursos para a habilitação desse profissional, as quais culminaram no CPA. Sua transferência para a universidade é decisiva na trajetória científica da Arquivologia no Brasil, representando a conquista de espaço no meio acadêmico. Afinal, esse é o primeiro de 17 cursos de graduação em Arquivologia que passariam a existir no país. A maioria desses cursos está vinculada academicamente à $\mathrm{CI}$, semelhantemente à classificação da Arquivologia na TAC do $\mathrm{CNPq}$, em vigor, que a subordina àquela disciplina (Conselho Nacional de Desenvolvimento Científico e Tecnológico, 1984). Somado a esses 17 cursos de graduação, cria-se em 2012 o Mestrado Profissional em Gestão de Documentos e Arquivos na Universidade Federal do Estado do Rio de Janeiro (UniRio), ${ }^{16}$ que passa a abrigar pesquisas sobre arquivos e Arquivologia.

Não menos relevante foi a atuação das 11 associações de arquivistas e de Arquivologia, com destaque para a $\mathrm{ABB}$, que funcionou durante 44 anos e que, nos últimos anos, compartilhou desafios com outras dez instituições congêneres. A importância dessas associações para a institucionalização da disciplina pode ser verificada nos cursos por elas realizados (Marques, 2007), bem como nos congressos nacionais, com temáticas diversas voltadas para a formação complementar dos arquivistas, e mesmo na publicação de um periódico voltado para temas arquivísticos, a revista Arquivo \& Administração, que circulou entre 1972 e 2014. 
Podemos afirmar que ao longo dessa trajetória a Arquivologia brasileira tem buscado sua autonomia científica, concomitantemente ao refinamento das suas parcerias com outras disciplinas. O arquivista, por sua vez, busca identidade profissional no âmbito da comunidade de profissionais, pesquisadores, docentes e discentes do campo da informação.

\section{CONSIDERAÇÕES FINAIS}

A Arquivologia francesa no século XXI é essencialmente prática e inspirada nas reflexões advindas das experiências dos arquivistas. A parte dedicada à teoria pura ainda é frágil, o que se evidencia pelo pequeno número de cursos de doutorado em Arquivologia até então (um em Archivistique et gestion des documents, em Angers, e outro em Histoire, em Paris), mas é verdade que ela foi reconhecida tardiamente como disciplina acadêmica - a maioria dos mestrados na área integra cursos profissionais e não acadêmicos.

Apesar disso, o pensamento arquivístico adapta-se facilmente ao mundo contemporâneo. A Gazette des Archives, por exemplo, revista francesa centenária e a única na área, na França, publica regularmente textos sobre questões e debates contemporâneos. A tecnologia digital está no cerne do pensamento arquivístico francês atualmente, da coleta de informações (como selecionar informações autênticas, confiáveis e íntegras?) e tratamento (como garantir a preservação, a longo prazo, da tecnologia digital?), até sua disponibilização (como promover o acesso garantindo a proteção dos dados pessoais?).

No Brasil, a formação e a busca por autoafirmação da Arquivologia como disciplina científica também foram consequências diretas e imediatas da necessidade prática de habilitação de profissionais especializados para a organização, a recuperação e a preservação dos arquivos do país. Podemos observar, portanto, a relevância da atuação do AN nessa trajetória, desde a promoção de cursos técnicos, que contribuíram para a criação do CPA e, depois, dos demais cursos de graduação da área, até a aquisição e tradução de obras imprescindíveis para o estudo do pensamento e das práticas arquivísticas internacionais.

Num entrecruzamento de experiências similares, tanto no Brasil como na França, a disciplina vem se desenvolvendo acadêmica e cientificamente mediante as demandas do mundo do trabalho. O número de mestrados e doutorados é ainda menor aqui do que no país europeu, embora já exista um número significativo de dissertações e teses com temas de interesse dos arquivos e da 
Arquivologia, produzidas em programas de pós-graduação de áreas diversas. Nesse sentido, aliando demandas e desafios práticos a reflexões científicas (mas não somente isto, pois há estudos eminentemente teóricos), pesquisas vêm sendo desenvolvidas especialmente na academia e publicadas em periódicos arquivísticos e de áreas afins, que têm abrigado questões que perpassam os arquivos, a Arquivologia, o campo da informação, a organização, a recuperação, o acesso e a preservação de documentos e informações, sobretudo na sua versão digital, que parece ser um dos maiores desafios contemporâneos internacionais.

Diante desse desafio e das características das suas configurações atuais, a Arquivologia francesa e a brasileira parecem se reencontrar nos cenários de interlocução internacional, que conjugam fazeres e saberes em torno do conhecimento e da atuação do arquivista, que não são somente dele, mas dele também. Mais do que nunca, o arquivista deve refletir com outros profissionais da informação, em uma lógica de responsabilidades compartilhadas. Menos restritas às fases dos arquivos (permanentes ou correntes), diante da complexidade do tratamento e da disponibilização dos documentos contemporâneos, as disciplinas passam a conjugar princípios, teorias, procedimentos e técnicas arquivísticas que abrangem as informações de maneira ampla.

As particularidades das configurações da Arquivologia num e noutro país parecem ocorrer em duas vertentes distintas: na França, mais em razão de questões teórico-epistemológicas, aparentemente mais avançadas; no Brasil, com arranjos político-institucionais influenciando os rumos da disciplina (hoje mais próxima da CI na vinculação dos cursos, na titulação dos professores, na produção de pesquisas e na classificação das áreas do conhecimento).

Dentre as questões que ainda carecem de estudos mais aprofundados estão, portanto, as configurações da formação e da pesquisa em Arquivologia na França, que, diferentemente do Brasil, não têm quase nenhuma aproximação com a CI, mesmo existindo a École Nationale Supérieure des Sciences de l'Information et des Bibliothèques (ENSSIB), que poderia ser mediadora de diálogos entre as duas disciplinas, como acontece com departamentos, institutos e centros de CI no Brasil que abrigam cursos de Arquivologia e pesquisas com temáticas arquivísticas. Mesmo a oferta de disciplinas de CI pela ENC não nos parece suficiente para identificar relações entre a Arquivologia e essa disciplina na França, uma vez que foram aproximações teóricas pontuais e sucintas, rapidamente abandonadas e aparentemente sem repercussões atuais naquele país. 
Estudos nesse sentido poderiam investigar como os dois países foram, nas suas grandes linhas, se distanciando quanto ao ensino de Arquivologia, o Brasil trilhando um percurso bastante peculiar, atualmente próximo da CI, mas buscando a identidade da disciplina arquivística.

\section{REFERÊNCIAS}

ACCORD CULTUREL ENTRE LE GOUVERNEMENT DE LA RÉPUBLIQUE FRANÇAISE ET LE GOUVERNEMENT DE LA RÉPUBLIQUE DES ÉTATS-UNIS DU BRÉSIL, 1948. Disponível em: https://francearchives.fr/en/facomponent/4dd133a71214039854b52f 13c49d798a7a2b19a0; acesso em: 17 jan. 2018.

ARCHIVES DE FRANCE. Historique des archives publiques en France. 2018a. Disponível em: https://francearchives.fr/article/37706; acesso em: 18 jan. 2018.

Liste des formations universitaires en archivistique. 2018b. Informações disponíveis em: http://www.archivesdefrance.culture.gouv.fr/archives-publiques/formations/formations-universitaires/liste-des-formations-par-niveau/; acesso em: 3 jan. 2018.

ASSOCIATION DES ARCHIVISTES FRANÇAIS. Abregé d'archivistique: príncipes et pratiques du métier d'archiviste. Paris, 2012.

BABELON, Jean-Pierre. Les archives: mémoire de la France. Paris: Découvertes Gallimard Culture et Societé, 2008.

BAUTIER, Robert-Henri. La phase cruciale de l'histoire des archives: la constituition des dépôts d'archives et la naissance de l'archivistique ( $\mathrm{XV}^{\mathrm{e}}$ - début du XIX ${ }^{e}$ siécle). Archivum, Paris, n.18, p.139-149, 1968.

BRAIBANT, Charles. Les archives de France: hier, aujourd'hui, demain. Conférence faite à la Societé de l'École des Chartes, le $1^{\text {er }}$ décembre 1949. Paris: Imprimerie Nationale, 1949.

CONSELHO NACIONAL DE PESQUISA E DESENVOLVIMENTO CIENTÍFICO E TECNOLÓGICO (CNPq). Áreas do conhecimento: classificação. Brasília, 1984.

DELMAS, Bruno. Naissance et renaissance de l'Archivistique française. Gazette des Archives, Paris, n.204, p.5-32, 2006.

. Trente ans d'enseignement de l'archivistique en France. Gazette des archives, Paris, n.141, p.19-32, 1988.

DIRECTION DES ARCHIVES DE FRANCE (DAF). Manuel d'Archivistique: théorie et pratique des archives publiques en France. Paris: Archives Nationales, 1991.

La pratique archivistique française. Paris: Archives Nationales, 1993.

DOUSSET, François. Présentation du manuel. In: DIRECTION DES ARCHIVES DE FRANCE. Manuel d'Archivistique: théorie et pratique des archives publiques en France. Paris: Archives Nationales, 1991. 
ESTEVÃO, Silvia Ninita de M.; FONSECA, Vitor Manoel M. da. A França e o Arquivo Nacional do Brasil. Acervo, Rio de Janeiro, v.23, n.1, p.81-108, jan./jun. 2010.

FREITAS, Adda Drugg de. Processamento de informações de registros médico-hospitalares. Dissertação (Mestrado em Biblioteconomia e Documentação) - Universidade Federal do Rio de Janeiro (UFRJ); IBBD. Rio de Janeiro, 1972.

LANGLOIS, Charles-Victor. La Science des Archives. Revue Internationale des Archives, des Bibliothèques et des Musées, Paris, v.1, n.1, p.7-25, 1895.

LANGLOIS, Charles-Victor; STEIN, Henri. Les archives de l'histoire de France. Paris: Alphonse Picard, 1891.

MARCILLOUX, Patrice. L'Archivistique à l'université: quel régime disciplinaire? Gazette des Archives, Paris, n.226, p.297-311, 2012.

MARIZ, Anna Carla de A.; JARDIM, José Maria; SILVA, Sérgio Conde de A. (Org.) Novas dimensões da pesquisa e do ensino da Arquivologia no Brasil. Rio de Janeiro: Móbile; Associação dos Arquivistas do Estado do Rio de Janeiro, 2012.

MARQUES, Angelica A. da C. Os espaços e os diálogos da formação e configuração da Arquivística como disciplina no Brasil. Dissertação (Mestrado em Ciência da Informação) Universidade de Brasília (UnB). Brasília, 2007.

Interlocuções entre a Arquivologia nacional e a internacional no delineamento da disciplina no Brasil. Tese (Doutorado em Ciência da Informação) - Universidade de Brasília (UnB). Brasília, 2011.

A investigação científica em Arquivologia e a sua busca de identidade. Pesquisa Brasileira em Ciência da Informação e Biblioteconomia (PBCIB), João Pessoa, v.12, p.7789, 2017.

MARQUES, Angelica A. da C.; RONCAGLIO, Cynthia; RODRIGUES, Georgete Medleg. A formação e a pesquisa em Arquivologia nas universidades públicas brasileiras: I Reunião Brasileira de Ensino e Pesquisa em Arquivologia. Brasília: Thesaurus, 2011.

MATOS, Maria Teresa N. de B. et al. (Org.) Perfil, evolução e perspectivas do ensino e pesquisa em Arquivologia no Brasil. Salvador: Ed. UFBA, 2015.

MINISTÈRE DE L'ÉDUCATION NATIONALE; MINISTÈRE DE L'ENSEIGNEMENT SUPÉRIEUR ET DE LA RECHERCHE. Dictionnaire des compétences, 2011. Disponível em: https://cache.media.enseignementsup-recherche.gouv.fr/file/Ressources_humaines/49/4/2011_repertoire_metiers_dicocompetences_199494.pdf; acesso em: 4 jan. 2018.

NEVES, Dulce Amélia de B.; ROCHA, Maria Meriane V.; SILVA, Patrícia. Cartografia da pesquisa e ensino em Arquivologia no Brasil: IV REPARQ. João Pessoa: Ed. UFPB, 2015.

NOUGARET, Christine. L'apport de l'Association des archivistes français à l'archivistique: 70 ans de Gazette des Archives. Gazette des Archives, Paris, n.204, p.33-57, 2006.

L'École des Chartes forme-t-elle encore des archivistes? Gazette des Archives, Paris, n.208, p.23-29, 2007. 
PÉROTIN, Yves. Le records management et l'administration américaine des archives: rapport de mission adressé a M. le Préfet de La Seine. Paris: Archives de la Seine et de la Ville de Paris, 1962.

PÉTILLAT, Christine; PRAX, Hélène. Les archives contemporaines ou l'arrivée du flux au quodien. In: DIRECTION DES ARCHIVES DE FRANCE. La pratique archivistique française. Paris: Archives Nationales, 1993.

SANTOS, Paulo R. Elian dos. Arquivística no laboratório: história, teoria e métodos de uma disciplina. Rio de Janeiro: Teatral; Faperj, 2010.

SCHELLENBERG, Theodore R. Documentos públicos e privados: arranjo e descrição. 2.ed. Rio de Janeiro: Fundação Getúlio Vargas, 1980.

WAILLY, Natalis. Éléments de Paléographie. Paris: Impremerie Royale, 1838.

\section{NOTAS}

${ }^{1}$ Duas das autoras deste texto participaram das três primeiras etapas da pesquisa, e as três autoras, da última etapa: a primeira delas consistiu em um projeto de iniciação científica, desenvolvido no âmbito da graduação em Arquivologia, que objetivou mapear a produção científica relacionada aos arquivos e à Arquivologia no Brasil. A segunda fase resultou em uma dissertação que investigou a trajetória da Arquivologia como disciplina científica no Brasil. Uma tese de doutorado coroou a terceira fase, investigando as interlocuções entre a Arquivologia internacional e a nacional no delineamento científico da disciplina no campo da informação. E, por fim, a quarta fase consistiu em um estágio pós-doutoral, realizado no Brasil e na França, sobre as contribuições francesas na institucionalização da Arquivologia no Brasil, com financiamento da Coordenação de Aperfeiçoamento de Pessoal de Nível Superior (CAPES).

${ }^{2}$ As referidas entrevistas foram realizadas entre maio e outubro de 2015, em Paris.

${ }^{3}$ François Guizot (1787-1874), dentre outros cargos, foi ministro da Instrução Pública e chefe do Gabinete; expediu ordens acerca do arranjo dos documentos públicos provinciais em 1839 (SCHELLENBERG, 1980).

${ }^{4}$ Todas as citações de obras publicadas em francês foram traduzidas por nós.

${ }^{5}$ Professor da Sorbonne e diretor dos Archives de France (1913-1929).

${ }^{6}$ Jacob-Nicolas Moreau, historiador e historiógrafo francês (1717-1803). Como historiador, escreveu inúmeros trabalhos e ensaios e criou o que se convencionou denominar "dépôt des chartes", destinado a recolher os textos oficiais sobre a história da França.

${ }^{7}$ Informações disponíveis em: https://archive.org/details/BrusselsCongress1910; acesso em: 4 jan. 2018.

${ }^{8}$ Segundo BABELON (2008), tanto os Archives Nationales como os Archives Départamentales (que, no Brasil, correspondem aos arquivos estaduais) são filhos da Revolução 
Francesa. Esses últimos foram criados pela lei de 5 Brumário, ano V (26 de outubro de 1796). Já os Archives Communales (equivalentes aos arquivos municipais no Brasil) existiam antes da Revolução Francesa.

${ }^{9}$ Armand Gaston Camus (1740-1804), desde a criação da Assembleia Nacional Constituinte é designado como secretário, em seguida eleito arquivista. Inspirou o artigo do regulamento dos Archives Nationales que prevê a organização de um serviço de arquivos. É ele quem redige um plano provisório de planejamento do depósito de arquivos e busca reconstituir os arquivos anteriores a esse período.

${ }^{10}$ Em 1897, a Direction des Archives nasce da fusão dos Archives Nationales com o Serviço de arquivos do Ministère de l'Intérieur, dentro do Ministère de l'Intruction Publique. Em 1936, torna-se Direction des Archives de France. Desde 1959, data da criação do Ministère des Affaires Culturelles, de André Malraux (1901-1976) - escritor e político francês, autor da renomada obra La condition humaine e primeiro ministro da Cultura (1959-1969) sob a presidência do General de Gaulle -, passa a ser uma das direções e, depois, em 2010, um dos serviços do Ministère de la Culture (Archives de France, 2018a).

${ }^{11}$ Informações disponíveis em: http://www.archives-nationales.culture.gouv.fr/fr/web/ guest/histoire-de-l-institution; acesso em: 4 jan. 2018.

${ }^{12}$ Informações disponíveis em: http://www.archivesdefrance.culture.gouv.fr/action-internationale/formations/; acesso em: 4 jan. 2018.

${ }^{13}$ Joseph-Marie de Gérando (1772-1842), estudioso francês, linguista, pedagogo e filantropo quando da criação, em 1821, da ENC.

${ }^{14}$ Segundo BABELON (2008), duas ordens se complementam para a criação da ENC (de 22 fev. e 11 nov. 1821).

${ }^{15} \mathrm{Se}$, por um lado, o acesso às obras francesas pode ser limitado às comunidades arquivística e histórica brasileiras (o que nos sugere a necessidade de maior detalhamento na descrição da trajetória dos arquivos e da Arquivologia na França), por outro lado, no Brasil há obras decorrentes de pesquisas acadêmicas e de eventos científicos que podem ser acessadas com facilidade para o estudo da disciplina no cenário brasileiro (MARQUES, 2007; 2011; SANTOS, 2010; MARQUES; RONCAGLIO; RODRIGUES, 2011; MARIZ; JARDIM; SILVA, 2012; MATOS et al., 2015; NEVES; ROCHA; SILVA, 2015).

${ }^{16}$ Há também cursos de especialização, como o de Gestão em Arquivos da Universidade Federal de Santa Maria (UFSM) e o de Organização de Arquivos do IEB/USP, que funcionou por 22 anos (1986-2008).

Artigo recebido em 1ํo de março de 2018.

Aprovado em 2 de maio de 2018. 